\title{
Editorial
}

\section{Los retos de la enseñanza de la criminología en Nicaragua}

The challenges of teaching criminology in Nicaragua

\author{
Óscar Castillo Guido \\ Decano Emérito de la ECPJ-UPOLI ${ }^{1}$ \\ derecho@upoli.edu.ni
}

La historia nicaragüense, está marcada por años de guerras, dictaduras, revoluciones y convulsiones sociales, esto no ha permitido ni aun en tiempos de paz consolidar un sistema de seguridad jurídica en materia de prevención del delito, ni ha permitido trazar una ruta en búsqueda de su modernización. En la actualidad aún persiste, un sistema sin posibilidad de formular ni evaluar políticas públicas encaminadas a la prevención del delito, el estudio del delincuente, la delincuensilidad, sus causas y el tratamiento de la víctima ${ }^{2}$.

Por otra parte, la crítica sobre este tema es entendida como un ataque al modelo de seguridad del país. Las cárceles siguen siendo espacios cerrados a la investigación criminológica y los datos oficiales son difíciles, cuando no imposibles, de conseguir. El avance hacia el cambio en estos años de democracia ha sido lento y no exento de dificultades en esta materia. Dentro del propio sistema, se ignora la figura del criminólogo como profesional, de igual forma no existe preocupación sobre la formación de este profesionista por parte de las facultades de derecho y de las ciencias sociales.

En cuanto a la práctica las actividades que debería realizar un profesional de la criminología en el quehacer diario son distribuidas a otros profesionales que poseen funciones u oficios parecidos, o a veces por el personal administrativo y en otras ocasiones por peritos forenses o criminalísticos cuyo objeto de estudio tiende a confundirse con la criminología.

Un ejemplo claro de esta ausencia se puede observar en los centros de atención a la violencia de género, juzgados especializados, centros penitenciarios u otras instancias de públicas. Para este caso, por tanto, el deber ser, es propiciar un tratamiento "integral" a las víctimas de violencia de género, por ello debe existir un equipo profesional compuesto por personas del campo de la psicología, el trabajo social, la educación y por supuesto con

\footnotetext{
${ }^{1}$ Miembro Fundador y Vocal de la Red Iberoamericana de la Criminología, Criminalística y Ciencias Forenses.

${ }^{2}$ Documento: "Proyecto de Diseño Curricular de la Licenciatura en Criminología de la UPOLI"., pág. 10
} 
personas profesionales formadas con un enfoque criminológico, que tengan como función principal asumir el tratamiento victimológico adecuado.

Por otra parte, también es importante señalar que una agravante de la ausencia del perfil profesional del criminólogo se manifiesta cuando en la empresa privada carece de estrategias y políticas en sus organizaciones, en materia de seguridad empresarial, prevención del delito y asesoría permanentes de expertos en la configuración de sistemas seguros de control, prevención y seguimiento. A pesar de que existen empresas de seguridad, estás no son más que entidades de prestación de servicios de vigilancia y monitoreo y no de prevención, todo esto por carecer de personal calificado en la materia.

Incorporar en la oferta académica de las Universidades, la Licenciatura en Criminología es un reto irrenunciable, para ello, es conviene analizar ¿Qué colectivos podrían realizar su formación en la criminológica? Por un lado, aquel colectivo del alumnado cuya formación básica será la criminología. Y por el otro, aquel colectivo del alumnado que tienen una formación básica en otra licenciatura, como la del Derecho, que debe ser complementarla con los estudios de criminología, para poder ejercer esa profesión básica en ámbitos relacionados con la criminalidad.

En este contexto, las actividades relacionadas con el mundo de la criminalidad deberán ser trabajadas, en principio por los licenciados en criminología. Semejante a lo que ocurre con el resto de las profesiones, por ello se deberán de regular al criminólogo, teniendo en cuenta que se debe establecer aquellos actos propios y exclusivos de esta profesión. Partiendo de esto estamos ante una excelente oportunidad para profesionalizar de una vez por todas aquellas actividades como las políticas públicas en materia de prevención, control y seguimiento de la criminalidad y del delincuente. Todas estas deben de ser desarrolladas por personas con formación especializada en la materia.

Así mismo, se debe exigir formación criminológica cuando el ejercicio de otra profesión como la del abogado, se desarrolle sobre cuestiones relacionadas con la criminalidad. En estos casos, la persona que realiza el trabajo como tal, deberá además tener amplia formación en criminología, o por lo menos deberá tenerse en cuenta dicha preparación en los conocimientos propios de la criminología. Incluso se podría ir ideando una doble titulación, en criminología y el de derecho, tal a como sucede en Europa. ${ }^{3}$

Bajo este panorama, no es difícil concluir, en una primera aproximación, que deberá requerirse formación criminológica, en aquellos ámbitos que tengan que ver con el núcleo del fenómeno criminal: sus sujetos, delincuente - víctima; el delito, como hecho social; y el

\footnotetext{
${ }^{3}$ https://www.google.com/search?q=dobles+titulaciones+en+europa\&oq=dobles+titulaciones+en+europa\&aqs=chrome..6 9i57.5791j0j8\&sourceid $=$ chrome $\& \mathrm{ie}=\mathrm{UTF}-8$
} 
sistema penal, como el complejo instrumento para hacerle frente, y en el que deben incluirse todos aquellos mecanismos de gestión y resolución de conflictos, alternativos a la punición, como la mediación. En este ámbito deben determinarse los espacios en los que debe exigirse la formación criminológica. Así como los espacios en los que se debe requerir la colaboración o por lo menos un informe preceptivo de un criminólogo.

Dentro de este núcleo, una segunda zona de reflexión la constituye todo el ámbito de la prevención, zona que se constituye desde el ámbito de la seguridad pública y privada. Cabe pensar que, por ejemplo, las personas encargadas de la seguridad pública tanto en los gobiernos centrales, los gobiernos locales y regionales, así como de las empresas u otras instituciones privadas, deben contar con esa formación.

No debemos descuidar, por último, el campo de la investigación, que constituye uno de los aspectos básicos del papel del criminólogo. Tanto desde la perspectiva de la investigación del hecho criminal (criminalística), como y fundamentalmente desde la perspectiva de la investigación básica (teorías criminológicas), así como de la investigación aplicada (las cifras de la criminalidad, el funcionamiento del sistema y de la realidad social que lo envuelve). Investigación que debe abarcar, siempre y en todo caso, la evaluación de las políticas y prácticas criminológicas. ${ }^{4}$

Finalmente, a estos retos que se perfilan desde el punto de vista profesional, debemos añadir los retos desde el punto de vista formativo. A pesar de la evolución democrática en Centroamérica, la Universidad, paradójicamente, aparece, en determinados aspectos, como un foco de resistencia a esos avances. Esto comporta que las titulaciones no siempre se desarrollen y planifiquen según las necesidades y requerimientos de las titulaciones, sino en consideración a factores como distribución de poderes entre los departamentos, las plantillas, la carga docente, etc.

En este sentido, consideramos que no es suficiente que los planes de estudios no se vinculen con las áreas de conocimiento, sino que se hace necesario que finalmente se reconozca e incorpore la criminología dentro del listado de áreas de conocimiento. Lo que no parece deseable y constituye un claro obstáculo para la adecuada programación y desarrollo de la licenciatura es tener que moverse entre un complejo mundo novedoso de formación, con intereses diversos y en ocasiones contrapuestos, quedando las decisiones pedagógicas y formativas condicionadas a las dinámicas de formaciones tradicionales y los intereses de cada entidad facultativa. En este sentido y de forma muy sintética, debemos tomar conciencia y trabajar en acciones como:

\footnotetext{
${ }^{4}$ Baratta, Alessandro (1986). Criminología crítica y crítica del derecho penal: introducción a la sociología jurídico-penal. Siglo XXI.
} 
Generar condiciones: Reconocer de una vez por toda la criminología como área de conocimiento, permitiendo de esa forma que profesores con diversa formación básica (derecho, psicología, sociología, educación, trabajo social, etc.), puedan concurrir en una facultad, precisamente porque se dedican a la docencia e investigación en criminología. Lo que permite integrar verdaderos equipos multidisciplinares de trabajo. Evitando con esto, que la formación en criminología se convierta en una parcela del poder y se vea finalmente determinada por intereses internos, ajenos a la propia formación.

Profesionalizar el sistema. Con todas las reservas y los cuidados que requiere el tema del control profesionalizado, conviene abandonar la idea de que el sistema penal y los espacios que lo rodean, pueden ser ocupados por voluntarios o por aquel personal excedente según cada lugar y momento.

Reforma de planes de estudios. Tan necesarios como oportunos de cara a contar con profesionales más dedicados a los problemas sociales, particularmente a los de la criminalidad, los derechos humanos y la justicia penal efectiva.

Oferta de postgrado en criminología. Que permitan desde la licenciatura en criminología, la formación postgraduada a estos u otras profesiones afines como la abogacía, la psicología, la medicina, que les permita actualizarse o formarse en el campo y que agreguen valor a su ejerció profesional contribuyendo con ello a una justicia penal efectiva.

Convenios. Se requiere suscribir al menos, protocolos de entendimiento entre el sistema de educación superior centroamericano (CSUCA; FUPAC; AUPRICA), a fin de homologar los planes de estudios que permitan incorporar al formación de la criminología en los distintos niveles de formación. De igual manera insertarlos en el Modelo de Armonización de los Sistemas de Educación Superior de los Países Centroamericanos, recogiendo con ello, un modelo de ingreso y titulación de dicha carrera, que ya operan con éxito en Guatemala, El Salvador y Costa Rica. ${ }^{5}$

Para nuestra Escuela de Ciencias Jurídicas y Políticas de la UPOLI, el reto queda asumido.

${ }^{5}$ http://www.csuca.org/docsscsuca/libros/ANALISISCOMPARATIVOYPROPOSITIVOPARALAARMONIZACION.pdf 